\title{
Crustal block rotations in Chinese mainland revealed by GPS measurements*
}

\author{
Wei Wang ${ }^{1,2,}$ Shaomin Yang ${ }^{1,3}$ and Qi Wang ${ }^{1,3}$ \\ ${ }^{1}$ Institute of Seismology, China Earthquake Administration, Wuhan 430071, China \\ ${ }^{2}$ Institute of Geophysics, China Earthquake Administration, Beijing 100081, China \\ ${ }^{3}$ Research Center of Space Science and Technology, China University of Geosciences, Wuhan 430074, China
}

\begin{abstract}
We simulate GPS horizontal velocity field in terms of rotations of crustal blocks to describe deformation behavior of the Chinese mainland and its neighboring areas. 31 crustal blocks are bounded primarily by $\sim 30$ Quaternary faults with distinct geometries and variable long-term rates of $<20 \mathrm{~mm} / \mathrm{a}$, and $1683 \mathrm{GPS}$ velocities were determined from decade-long observations mostly with an averaged uncertainty of $1-2 \mathrm{~mm} / \mathrm{a}$. We define GPS velocity at a site by the combination of motion of rigid block and elastic strain induced by the fault that is locking during a seismic cycle. Model velocities predicted from the preferable block model match well with the GPS velocities to an uncertainty of $\sim 1.7 \mathrm{~mm} / \mathrm{a}$. The slip rates inferred from this model is in a range of 6-18 mm/a for the major faults in Tibet and its margins and 1-4 mm/a in eastern China, consistent with geological observations. Our numerical simulation suggests that the crustal blocks deform internally at a level of $\sim 10 \times 10^{-9} /$ a, quite small in comparison with significant deformation localized along fault zones of $50-100 \mathrm{~km}$ wide. We conclude that the pattern of continental deformation is not continuous-like but block-like, and the tenet of plate tectonics may be applicable to characterize the active deformation in Asia.
\end{abstract}

Key words: GPS; Chinese mainland; active block; block rotation; crustal deformation

CLC number: P315.72 5 Document code: A

\section{Introduction}

A quantitative description of the deformation of Asia in response to Indian plate's convergence is key to understand long-term crustal deformation processes in continents, and has important implications for lithospheric dynamics and earthquake hazard assessment (Replumaz and Tapponnier, 2003). Previously, the velocity field was mainly inferred from earthquake information and Quaternary fault slip rates (Holt et al, 2000). In recent years, numerous new observations in order to obtain velocity field within the Asia have been carried out rapidly. Space geodesy especially the GPS measurements have been covered over the entire actively deforming zone in Asia for the recent 10 years with sufficient precision and density (Wang et al, 2001; 2003; Zhang et al, 2004), to allow tests of various kinematic and dynamic models of continental deformation. These

\footnotetext{
* Received 13 July 2009; accepted in revised form 27 October 2009; published 10 December 2009.

^ Corresponding author. e-mail: wangweigps@126.com.
}

GPS measurements have shed some new insights for the mode of continental tectonics, and also provide important constraints for us to understand, identify and construct these kinematic and dynamic models. Because the pre-existing controversy about whether continental deformation is more accurately described by the relative motions of a few blocks (Avouac and Tapponnier, 1993; Peltzer and Saucier, 1996) or by a more spatially continuous process (England and Molnar, 1997) remains largely unresolved, in what manner the present-day velocity field, with high precision and spatial resolution, has reflected is a critical study under new situations (England and Molnar, 2005).

Preliminary tests demonstrate that present-day crustal deformation in the Chinese mainland especially in the Tibetan plateau might act as a more spatially continuous process. Dynamic models of a thin viscous sheet have performed a good fit to the GPS observations (Holt et al, 2000; Yang et al, 2005). However, previous studies demonstrate that geodetically measured steady-state interseismic surface velocities largely contain informa- 
tion about the motion of crustal blocks and elastic strain accumulation induced by the fault locking (Meade, 2007). Yet, these viscous sheet models have neglected the brittle upper crust and cannot reflect the mechanical behavior of fault slip, interseismic displacement and fault rupture in this upper layer. Such goodness of fit to the GPS observations neither proves the continuum concept nor precludes the block-like model (Thatcher, 2007).

Former studies of active tectonics show that Chinese mainland is comprised of crustal or lithospheric blocks at different scales (Deng et al, 2002) which behave as coherent motion, and recent GPS observations have confirmed the existence of these active blocks (Zhang and Zhu, 2000; Wang et al, 2003; Li et al, 2003). In other actively deforming zones such as western United States and New Zealand, block models have successfully interpreted various observations (McCaffrey, 2005; Wallace et al, 2004). These results from different regions suggest that rotations of elastic blocks within the continent may play a predominant role in taking up most of the convergence across the plate boundary. Because of the complex tectonic setting, unique strain conditions and its great spatial extent, whether the block model can image the characteristics of present-day deformation of Asia, especially the kinematics at the Indian-Eurasian plate collision zone needs more careful study.

Here, we take advantage of more accurate GPS measurements to construct the active block model. To interpret the GPS velocity field, we model the GPS velocities accounting simultaneously for the effects of block rotations, elastic strain induced by the block-bounding fault locking and internal strain within the blocks. This approach allows us to find an internally consistent result that ensures the compatibility of the block motions and elastic strain accumulation across faults. The purpose of our numerical simulation is to utilize a finite number of active blocks to describe the active deformation of the Chinese mainland and its vicinity, and to suggest that the present-day deformation in the Tibetan plateau can be described as low-speed motions of coherent blocks that can take up most of the continental deformation due to the Indian-Eurasian plate collision.

\section{Inversion method}

The motion of a rigid plate can be described by spherical angular velocities (Euler vectors). But with regard to the motion of continental block, in addition to its rotation, the elastic strain due to the block-bounding fault's locking could not be neglected. At a given point, the elastic strain is related to the distance from the block-bounding fault and also to the fault's geometry and its movement pattern. According to this, the velocity $\boldsymbol{v}_{R}$ of a surface point $R$ within a block which has a Euler vector of $\boldsymbol{\Omega}_{0}$ can be specified by

$$
\boldsymbol{v}_{R}=\boldsymbol{\Omega}_{0} \times R+\sum_{i=1}^{k} v_{i}\left(R, \boldsymbol{\Omega}_{i}, R_{i} f_{i}\right),
$$

where $\boldsymbol{\Omega}_{i}(i=1,2, \ldots, k)$ represents the Euler vector of the $i$ th block adjacent to the block $\boldsymbol{\Omega}_{0}, R_{i}, f_{i}$ represents the bounding fault's locations and geometry parameters respectively, and $v_{i}$ represents the elastic strain caused by the bounding fault's slip.

The structural slip across a block-bounding fault is the difference in the linear velocities of the two adjacent blocks, calculated from the Euler vectors at a point of interest on the fault, and the mechanical behavior of the fault determines the temporal and spatial distribution of the strain surrounding the fault. Generally, because of friction between the two sides of fault surface at the brittle upper crust, the upper crust is locked during the interseismic period, and this locking gives rise to elastic strain accumulation that causes across-fault velocity gradients to be smooth rather than abrupt. When the stress across the fault surface exceeds the strength of the fault, the fault surface is ruptured abruptly, and the earthquake happens. Subsequently the earthquake results in the release of the elastic strain. So in a seismic cycle, the brittle upper crust behaves as time dependent stick-slip (Savage, 2000); below the locking depth, the friction correlated with the temperature condition decreases rapidly, and the fault surface at this depth behaves as time invariant creeping-slip which can be calculated from the relative rotation of the two adjacent blocks.

We use the elastic half-space dislocation model based on the formulations of Okada (1985) to calculate the elastic deformation due to the fault locking

$$
v_{i}\left(R, \boldsymbol{\Omega}_{i}, f_{i}\right)=\varphi G\left(R, R_{i}, f_{i}\right)\left[R_{i} \times\left(\boldsymbol{\Omega}_{i}-\boldsymbol{\Omega}_{0}\right)\right],
$$

where $G$ is the Green's function at surface point due to the slip along fault surface, determined by the site position and fault geometry. Here we use a parameter called "locking coefficient"(varied within $[0,1]$ ) (McCaffrey, 2005; Wallace et al, 2004), defined as $\varphi=1-v / v_{0}$, where $v$ and $v_{0}$ represent the slip rate in reality and the predicted 
long-term slip rate calculated from the relative motion of the adjacent blocks respectively. $\varphi$ represents the extent to which a fault is locked (McCaffrey, 2005; Wallace et al, 2004), and reflects the true conditions of fault behavior at different depth and different position. We assume that GPS velocities throughout the interseismic period are approximately time invariant and neglect the effect of postseismic relaxation, consistent with a relatively high viscosity $\left(>10^{19} \mathrm{~Pa} \cdot \mathrm{s}\right)$ for the lower crustupper mantle (Meade, 2007). If $\varphi=1$, the fault is fully locked and there is no creep on the fault in the interseismic period; if $\varphi=0$, the fault is creeping at the full long-term slip rate, and this represents the behavior of the ductile part of the fault below the upper brittle layers. The parameter $\varphi$ can be fixed, but can also be estimated by GPS data. The parameter $\varphi$ flexibly reflects the complexity and uncertainty of the fault behavior, and reflects the true locking depth (McCaffrey, 2005; Wallace et al, 2004).

A distinct character of the continental blocks is the existence of secondary faults within the blocks, which may give rise to small internal deformation, especially in the Tibetan plateau, Sichuan and Yunnan, where earthquakes are distributed more widely. We utilize the uniform strain rate to represent the internal deformation induced by the secondary fault within the blocks. Hence, the overall velocity of a point $R$ can be defined by

$$
\begin{gathered}
\boldsymbol{v}_{\mathrm{R}}=\Omega_{0} R+ \\
\sum_{i=1}^{k} \varphi_{i} G\left(R, R_{i}, f_{i}\right) R_{i}\left(\boldsymbol{\Omega}_{i}-\Omega_{0}\right)+T\left(R-R_{0}\right),
\end{gathered}
$$

where $R_{0}$ is the centre of mass of a block, $T$ is the strain tensor (Savage et al, 2001).

If the number of GPS observations is $n$ (two times of the GPS sites), the number of blocks is $m$ and the number of fault coefficients is $k$, we use the objective function (4) to estimate the Euler vectors of $m$ blocks and the locking coefficients of $k$ faults, and to approach a best fit between the predicted velocity $V_{\mathrm{i}}$ and the observed velocity $V_{i}^{\text {GPS }}$ (the velocity uncertainty is $\sigma_{i}$ ):

$$
\begin{aligned}
& o\left(\boldsymbol{\Omega}_{\{i \leq m\}}, \boldsymbol{\varphi}_{\{i \leq k\}}=\right. \\
& \quad \frac{\sum_{i=1}^{n}\left(V_{i}^{\mathrm{GPS}}-V_{i}\right)^{2}}{\sigma_{i}^{2}}=\min , \quad(n>>3 m+k) .
\end{aligned}
$$

It should be noted that, when estimating the Euler vectors and the locking coefficients simultaneously, the observation equation is nonlinear, and these two kinds of parameters are strongly coupled. The inversion is implemented by DEFNODE program (McCaffrey, 2005; Wallace et al, 2004), which estimates the parameters by simulated annealing method, in search of the overall optimal parameters. To find parameter values that minimize the misfit, this method applies simulated annealing to downhill simplex minimization (Press et al, 1989), and a penalty function is used to keep the parameter of locking coefficient between 0 and 1 , as done by McCaffrey (2005) and Wallace et al (2004).

\section{Active block model}

Active block is defined as a coherent, lithospheric or crustal element which is bounded by Quaternary faults (Zhang et al, 2003). Conventional methods, used to determine the geometric and kinematic information for these faults, include geomorphic, geological and seismological studies (England and Molnar, 2005). Nowadays, GPS measurements can be considered a tool to identify possible shear zones that do not have distinct geomorphic markers or obvious slip, and hence, to make the fault trace more exact and the block boundary more reasonable, geologically and tectonically.

Because of the widely distributed Quaternary faulting, there might be diversified candidate outlines regarding to the block division. For instance, there are more than ten active faults which have different slip rates ranging from 2-9 mm/a in Yunnan and Sichuan. As far as the whole continent, there are much more active faults and tectonic elements. Here we construct a block model based on Zhang et al (2003)'s active block model in the Chinese mainland and its vicinity, and refer to Chen's block model in the Tibetan Plateau (Chen et al, 2004a, b). Our purpose is to use a finite number of spherical blocks to construct kinematic model in the Chinese mainland with existing GPS data. Here, we adequately take into account the activities across the block boundary and the difference of the motions between the adjacent blocks, in order to make the tectonic meaning more exact and the block scale more appropriate.

We have readjusted the previous block boundary based on our updated GPS velocity field. The block boundary and the bounding faults are shown by Figure 1 . For instance, in the regions east of Indo-Myanmar trench and south of Red River fault, we subdivide these regions into Myanmar (MY), West Yunnan (WY), South Yunnan (SY), Indochina (IC) blocks, separated by Di- 
enbienphu, Sagaing, Nantinghe faults, respectively. The East Yunnan (EY) block is bounded by Lijiang-Xiaojinhe, Anning-Zemu-Xiaojiang, and Red River faults. The East Qiangtang-West Sichuan (QS) block is limited to the east by Lijiang-Xiaojinhe fault, to the west by Shuanghu fault.

In the western part of China, the huge, strike-slip faults cut the Tibetan plateau into some sliver-shaped structures, oriented in the nearly west-east direction, such as Himalaya, Lhasa, Qaidam, Qilianshan Mountain, Tianshan Mountain, in comparison with block-shaped structures in the eastern part of China, such as South China, Ordos blocks. Studies of active tectonics suggest that the blocks in western China may be subdivided into smaller blocks. For example, in the north-eastern part of Tibet, Wang et al (2003) subdivide this region into Qaidam and Xining blocks, cut by the Elashan fault, and the
GPS observations have confirmed that these adjacent blocks have distinct motion tendency (Wang et al, 2003); and in southern Tibet, Chen et al (2004b) subdivide the Lhasa block based on the activity of Thakkola and Yadong-Gulu rifts. In contrast to former studies in southern Tibet, here we take the Lhasa and Himalaya blocks as a whole region, and then subdivide it further into Pamir-Kashmir (PA), Ali (AL), Saga (SG), Xigaze (XG) and LinZhi (LZ) blocks from west to east, based on Karakorum-Jiali fault and Thakkola, Tangra-Yum and Yadong-gulu rifts, although there are studies indicating that the Yarlung Zangbo suture has certain amount of right-lateral slip (Chen et al, 2004b).

Hence, our preferable block model is composed of31 elements, including two mechanical kinds of block elements. In the first group, these blocks are rigid obviously, and the strength of these blocks is comparable to

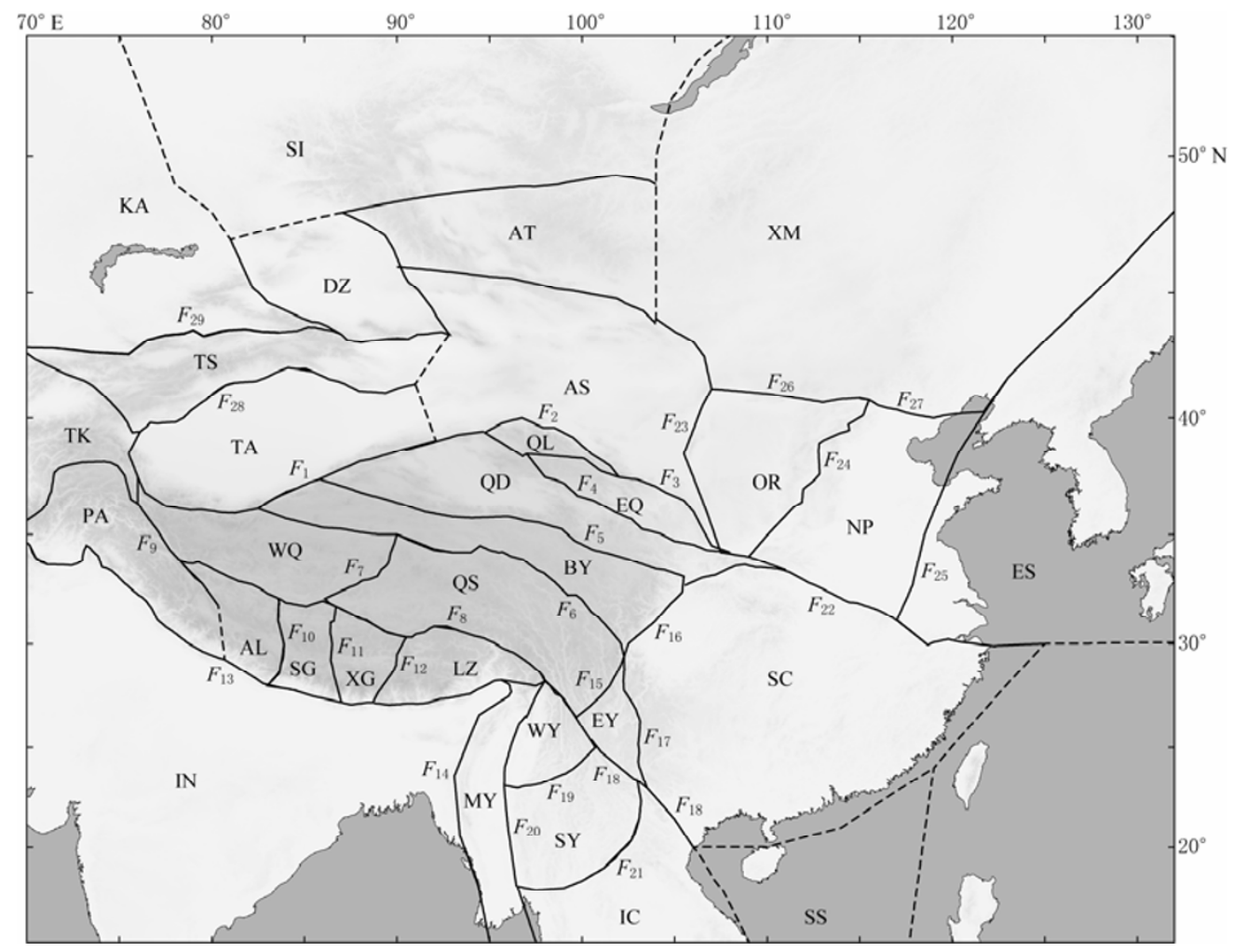

Figure 1 The block boundary of the model. AL: Ali; AS: Alashan; AT: Altay; MY: Myanmar; BY:Bayankala; DZ: Dzunggar; EQ: East Qilian; ES: East Shandong and Northeast China; EY: East Yunnan; IC: Indochina; IN: India; KA: Kazakh; LZ: Lin Zhi; NP: North China Plain; OR: Ordos; PA: Pamir-Kashmir; QD: Qaidam; QL: Qilian Shan; QS: East Qiangtang-west Sichuan; SC: South China; SG: Saga; SI: Siberia; SS: South Sea; SY: South Yunnan; TA: Tarim; TK: Tadijk; TS: Tian Shan; WQ: West Qiangtang; WY: West Yunnan; XG: Xigaze; XM: Xing'an-East Mongolia; Block-bounding faults: 1. Altyn Tagh; 2. QilianShan; 3. Haiyuan; 4. Nanqilianshan; 5. KunlunShan; 6. Xianshuihe; 7. Shuanghu; 8. Karakorum-Jiali; 9. Karakorum; 10. Thakkola; 11. Tangra-Yum; 12. Yadong-gulu; 13. Himalaya; 14. Indu-Myanmar Thrust; 15. Lijiang-Xiaojinhe; 16. LongmenShan; 17. Anning-Zemu-Xiaojiang; 18. Red River; 19. Nantinghe; 20. Sagaing; 21. Dienbienphu; 22. Qinling-Dabie; 23. Yinchuan-Jilantai; 24. Shanxi Graben; 25. Tan-lu; 26. Daqingshan; 27. Zhangjiakou-Penglai; 28. South Tianshan Mountain; 29. North Tianshan Mountain. 
the lithospheric plate, such as South China, Tarim, Alashan, and Ordos blocks. Because of the large scale of these blocks, the strain induced by the block-bounding faults has little influence on the motion of these blocks. Another category of blocks, they are bounded by thrust or normal faults. Strictly speaking, such blocks are not rigid, but their deformation is usually coherent with motions along their boundaries and may be treated as equivalent to deformation along the block rims (Replumaz and Tapponnier, 2003). If the strain induced by the block-bounding fault's locking and internal strain is removed, these blocks also show coherent movement.

\section{Data and analysis}

In the modeling, we use velocities of 1683 GPS sites (Figure 2). Our velocity field represents a combination of horizontal velocity solution obtained by our own data analysis using GIPSY software and published velocities from other groups. The GPS data are mainly from Crustal Movement Observation Network of China (CMONOC) (Niu et al, 2005) which includes three-epoch large campaigns conducted in 1999, 2001 and 2004 for the entire network. Meanwhile, the data are supplemented by numerous other domestic and international

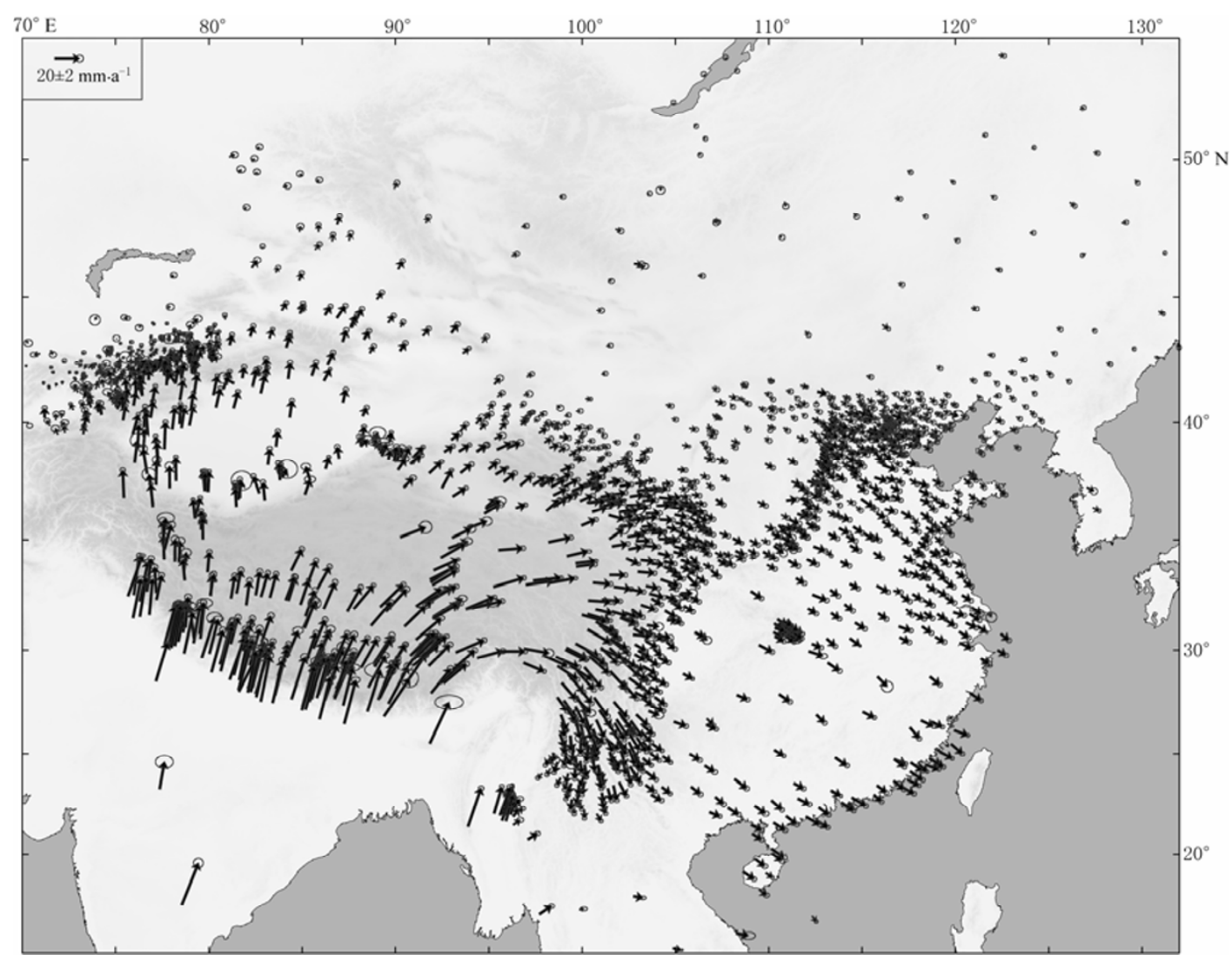

Figure 2 The GPS velocity field with respect to the stable Eurasian plate (ellipses represent $67 \%$ confidence interval).

projects. For example, the GPS data of Tianshan Mountain are supplemented by UNAVCO data archives (Yang et al, 2008).

Two types of GPS network solutions are utilized in our study (Yang et al, 2008). For the data prior to 1996, we process the data of local network together with a global network of 20-40 permanent stations, and satellite orbits are estimated in these solutions. For the data from 1996 to 2006, we use a regional solution strategy by combining campaign data with a regional network of continuous IGS (International GNSS Service) stations, and fix the precise orbit provided by the JPL (Jet Propulsion Laboratory)'s submission to IGS. The daily solutions are then transformed into the ITRF2000 system using seven parameter similarity transformation. The coordinates in the ITRF2000 reference frame and their covariance matrix from the daily GPS solutions are used to estimate site positions and velocities at the epoch 2000.0 by a standard weighted least squares adjustment (Yang et al, 2008). The uncertainty of site velocities de- 
rived by ourselves is less than $1.5 \mathrm{~mm} / \mathrm{a}$ for CMONOC and averaged 1-3 mm/a for other surveys. The velocity solutions for other regions, such as Mongolia, India, Indo-China, Myanmar, etc., are from published papers (Calais et al, 2003; Paul et al, 2001; Banerjee and Bürgmann, 2002; Vigny et al, 2003). We then combined the solutions from different research groups into a common reference frame ITRF2000, by estimating a seven parameter transformation based on common IGS stations. Then we derived the velocity field with respect to the Eurasia-fixed frame by minimizing velocities at $\sim 10$ sites distributed at the stable Eurasian plate. The mean uncertainty is less than $2 \mathrm{~mm} / \mathrm{a}$. Site velocities that are grossly inconsistent with neighboring stations are removed in the modeling.

We divide the block-bounding faults into small segments, define nodes on the fault surfaces to represent the fault geometry, and then use the fault parameters compiled by England and Molnar $(1997,2005)$ to compute the Green's function in the modeling. The dip angle of strike-slip fault is defined nearly $90^{\circ}$ whereas the normal or reverse fault has a dip angle of $\sim 45^{\circ}$, with the exception of Himalayan front, which dips $10^{\circ}$ northward. The locking depth is defined as $30 \mathrm{~km}$, the upper $10 \mathrm{~km}$ of the fault is fully locked with the locking coefficient fixed to 1, while the locking coefficient between 10-30 km is set free and adjusted in the modeling, and the fault below $30 \mathrm{~km}$ slip freely at the full long-term slip rate.

Two approaches have been adopted when we simulate the GPS horizontal velocity field. One is to treat the blocks as rigid, and neglect their internal strain, only considering the effects of block rotations and fault locking. Another one is to treat the blocks as elastic, accounting simultaneously for block rotations, fault locking and internal strain within the blocks. The weighted RMS misfit is $1.73 \mathrm{~mm} / \mathrm{a}$ for the first approach whereas the weighted RMS misfit is $1.50 \mathrm{~mm} / \mathrm{a}$ for the second approach.

1) On the whole, when the internal strain parameters are estimated, we obtain a better modeling result, especially for the blocks in the Tibetan plateau, and if the internal strain neglected, we obtain a little worse result. But in other regions outside the Tibetan plateau, whether or not the internal strain is estimated, the modeling result doesn't change at all;

2) Whether or not the internal strain is estimated doesn't change the Euler vectors significantly, but has some influences on the slip rate estimates for some faults averaged $\sim 3 \mathrm{~mm} / \mathrm{a}$, such as Himalayan front, South
Tianshan Mountain, Xianshuihe faults;

3) The internal strain rates range from $>15 \times 10^{-9} / \mathrm{a}$ for some blocks in the Tibetan plateau and Tianshan Mountain, to $<5 \times 10^{-9} / \mathrm{a}$ in the South China, Tarim, Ordos blocks.

Table 1 lists the modeling results, including the RMS misfit of each block when internal strain is not adjusted; the Euler vectors of each block when internal strain not adjusted. The block motion velocities and fault slip rates are plotted in Figure 3, which could reflect the first-order features of the continental tectonics (the results are based on the approach when internal strain is not adjusted, and the block motions are with respect to the block of Siberia (SI)). GPS velocity residuals (with $67 \%$ confidence ellipses) are plotted in Figure 4 by the approach when internal strain parameters are not adjusted.

Figure 3 shows the velocity of each block's movement from our preferred model, which is consistent with

Table 1 The results of the model

\begin{tabular}{|c|c|c|c|c|c|}
\hline Block & $N$ & Nrms & $\lambda /{ }^{\circ} \mathrm{E}$ & $\varphi /{ }^{\circ} \mathrm{N}$ & $\omega /^{\circ} \cdot \mathrm{Ma}^{-1}$ \\
\hline $\mathrm{AL}$ & 13 & 1.71 & $69.9 \pm 3.3$ & $33.2 \pm 2.5$ & $0.668 \pm 0.103$ \\
\hline AS & 100 & 1.59 & $104.5 \pm 1.7$ & $22.2 \pm 0.8$ & $-0.154 \pm 0.017$ \\
\hline $\mathrm{AT}$ & 9 & 1.08 & $103.2 \pm 10.5$ & $33.3 \pm 10.8$ & $-0.107 \pm 0.083$ \\
\hline MY & 7 & 2.39 & $104.5 \pm 3.7$ & $20.1 \pm 1.6$ & $-1.563 \pm 0.381$ \\
\hline BY & 40 & 1.61 & $98.9 \pm 0.9$ & $19.6 \pm 0.4$ & $-0.583 \pm 0.043$ \\
\hline DZ & 25 & 1.12 & $74.5 \pm 3.8$ & $48.8 \pm 7.6$ & $0.280 \pm 0.063$ \\
\hline EQ & 65 & 1.03 & $104.0 \pm 2.3$ & $20.1 \pm 0.8$ & $-0.303 \pm 0.043$ \\
\hline ES & 82 & 1.09 & $134.4 \pm 2.9$ & $48.2 \pm 1.7$ & $0.215 \pm 0.013$ \\
\hline EY & 39 & 1.98 & $72.9 \pm 7.1$ & $8.2 \pm 0.4$ & $-0.249 \pm 0.083$ \\
\hline IC & 6 & 1.67 & $102.7 \pm 3.2$ & $6.0 \pm 0.1$ & $-0.370 \pm 0.069$ \\
\hline IN & 58 & 1.30 & $10.6 \pm 2.2$ & $24.5 \pm 0.1$ & $0.365 \pm 0.007$ \\
\hline KA & 34 & 1.43 & $81.8 \pm 7.7$ & $35.7 \pm 8.2$ & $-0.057 \pm 0.027$ \\
\hline $\mathrm{LZ}$ & 19 & 1.57 & $96.3 \pm 1.0$ & $17.2 \pm 0.8$ & $-0.910 \pm 0.148$ \\
\hline NP & 227 & 1.32 & $140.7 \pm 7.8$ & $61.3 \pm 5.3$ & $0.125 \pm 0.012$ \\
\hline OR & 118 & 1.03 & $173.2 \pm 31.5$ & $68.8 \pm 11.1$ & $0.076 \pm 0.015$ \\
\hline PA & 23 & 2.05 & $48.9 \pm 19.9$ & $27.7 \pm 4.9$ & $0.266 \pm 0.133$ \\
\hline QD & 72 & 1.83 & $103.7 \pm 0.6$ & $24.2 \pm 0.4$ & $-0.420 \pm 0.018$ \\
\hline QL & 16 & 1.03 & $81.5 \pm 19.2$ & $64.3 \pm 77.4$ & $0.146 \pm 0.124$ \\
\hline QS & 73 & 3.27 & $95.2 \pm 0.2$ & $23.1 \pm 0.2$ & $-1.135 \pm 0.027$ \\
\hline $\mathrm{SC}$ & 136 & 1.09 & $207.8 \pm 8.3$ & $59.9 \pm 4.0$ & $0.093 \pm 0.003$ \\
\hline SG & 26 & 1.84 & $71.9 \pm 3.5$ & $35.0 \pm 3.4$ & $0.716 \pm 0.127$ \\
\hline SI & 10 & 1.44 & & & \\
\hline SS & 7 & 1.53 & $72.6 \pm 21.9$ & $-21.9 \pm 6.2$ & $-0.086 \pm 0.043$ \\
\hline SY & 36 & 3.15 & $94.4 \pm 1.3$ & $22.3 \pm 1.0$ & $-0.692 \pm 0.081$ \\
\hline TA & 55 & 1.25 & $101.6 \pm 0.8$ & $37.5 \pm 1.1$ & $-0.417 \pm 0.023$ \\
\hline TK & 31 & 1.72 & $67.3 \pm 5.9$ & $39.5 \pm 4.5$ & $0.337 \pm 0.076$ \\
\hline $\mathrm{TS}$ & 183 & 1.68 & $59.7 \pm 22.6$ & $38.9 \pm 14.1$ & $0.062 \pm 0.047$ \\
\hline WQ & 20 & 1.67 & $61.2 \pm 4.0$ & $37.1 \pm 2.6$ & $0.392 \pm 0.051$ \\
\hline WY & 24 & 1.80 & $86.7 \pm 2.6$ & $26.2 \pm 3.0$ & $-0.479 \pm 0.126$ \\
\hline XG & 16 & 1.61 & $104.3 \pm 2.7$ & $12.4 \pm 0.4$ & $-0.499 \pm 0.095$ \\
\hline $\mathrm{XM}$ & 113 & 1.02 & $141.2 \pm 12.0$ & $68.2 \pm 9.1$ & $0.073 \pm 0.009$ \\
\hline
\end{tabular}

Note: Block is the block name abbreviations in Figure $1 ; N$ is the number of GPS sites in each block; Nrms is the normalized Rms misfit when internal strain is not adjusted; $\lambda, \varphi$ and $\omega$ give the Euler vector for the block rotation relative to the block of Siberia when internal strain is not adjusted, negative rotation rates indicate clockwise motion; the block SI (Siberia) is the reference block for other block motions, and is assumed to be fixed. 


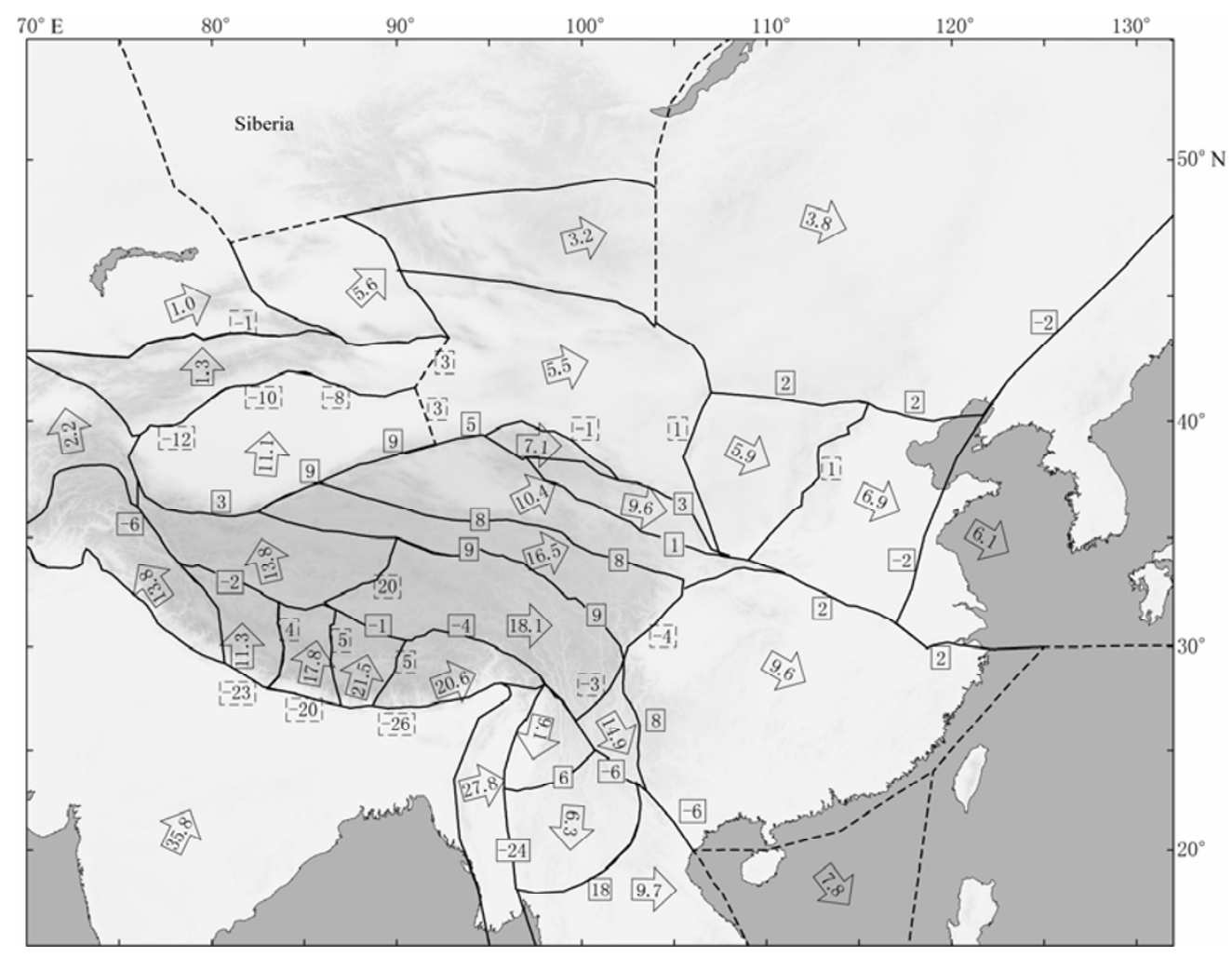

Figure 3 Block velocities and fault slip rates [the results are based on the approach when internal strain not adjusted, and the block motion velocities are with respect to the block of Siberia (SI)]. The numbers in the arrows indicate the block motion velocities. The numbers in the solid-line quadrangles indicate the slip rates of strike-slip faults, the positive numbers indicate left-lateral slip, and the negative numbers indicate right-lateral slip; the numbers in the dashed-line quadrangles indicate the rates of thrust or normal faults, the positive numbers indicate extension, and the negative numbers indicate convergence.

previous studies (Wang et al, 2003; Li et al, 2003). For instance, the velocities of South China, Dzunggar, Tarim blocks are $\sim 9.6 \mathrm{~mm} / \mathrm{a}, \sim 5.5 \mathrm{~mm} / \mathrm{a}, \sim 11.1 \mathrm{~mm} / \mathrm{a}$, respectively. Figure 3 shows evidence that crustal blocks bounded by major faults in Tibet have distinct motion velocities and distinct lateral extrusion.

We have compared the block motion results from our preferred model to that of Li et al (2003) by statistical analysis, and comparison shows that there is no obvious discrepancy between these two results. $\mathrm{Li}$ et al (2003) construct a 10-element block model of the Chinese mainland, with a different block outline, calculate the block rotation parameters individually, and eliminate the sites at the block boundaries. We select six blocks with similar definition from their study, to make comparison with that of ours. These blocks are Tarim, Dzunggar, Alashan, North China, South China and Ordos blocks. The standard deviation of the block motion velocities is $1.7 \mathrm{~mm} / \mathrm{a}$, the standard deviation of the block motion azimuths is $15^{\circ}$, and both show good agreement. Although we utilize much more GPS data sets and choose a more refined block outline, the discrepancy is little within the data uncertainty. It may be because that these selected blocks are located in stable regions outside the Tibetan plateau, with small internal deformation, and the block-bounding faults have little influences on the block interior.

Given the block rotations of individual blocks, the relative motions across the block boundaries are calculated and the velocity differences can be used to predict the long-term fault slip rates and compared with the Quaternary or GPS inferred fault slip rates. However, long-term geological slip rates remain largely controversial for some faults such as Altyn Tagh and Karakorum, ranging from $\sim 5 \mathrm{~mm} / \mathrm{a}$ to $\sim 30 \mathrm{~mm} / \mathrm{a}$. Our results favor the lower bound of the geological slip rates in Tibet, consistent with the Quaternary slip rates used by England and Molnar (1997) and also consistent with the GPS inferred low slip rates (Bendick et al, 2000; Wang et al, 2001). For instance, our model shows that the 
left-lateral slip rate for Altyn Tagh is $\sim 9 \mathrm{~mm} / \mathrm{a}$; the left-lateral slip rate for Kunlun is $\sim 8 \mathrm{~mm} / \mathrm{a}$; the right-lateral slip rate for Karakorum is $\sim 6 \mathrm{~mm} / \mathrm{a}$, etc. These fault slip rates are 2-5 times lower than the upper bound of geologic estimates. Although the origin of the slip rate discrepancy is contentious and currently unresolved, Thatcher (2007) suggests that these relatively low slip rates obtained from GPS measurements are intrinsic to the GPS data themselves and are compatible with current block motions in Tibet.

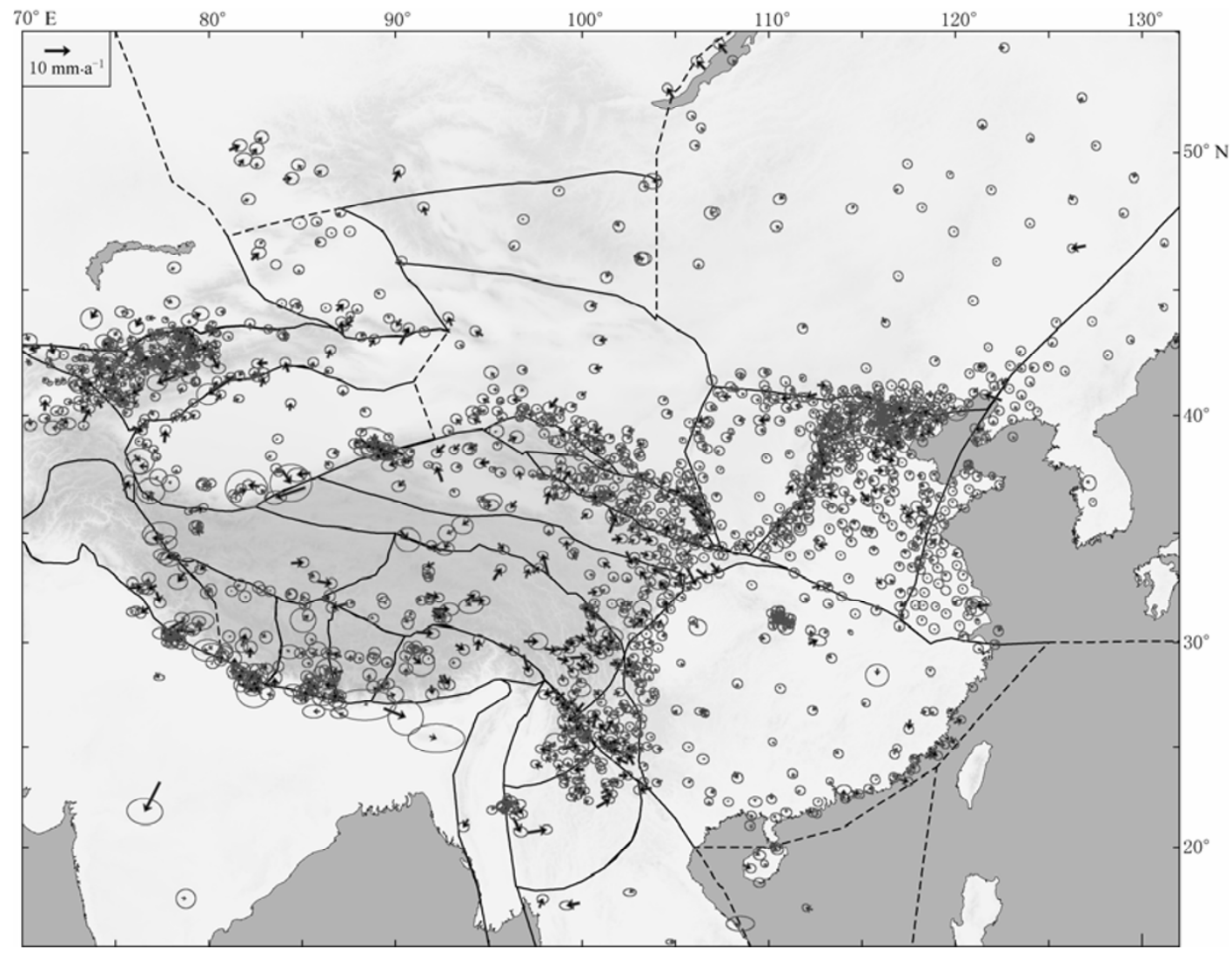

Figure 4 GPS velocity residuals of the model (ellipses represent $67 \%$ confidence interval; the residuals are based on the results when internal strain parameters are not adjusted).

\section{Discussion and conclusions}

GPS measurements uniquely quantify present-day deformation in the Chinese mainland that can be simply and usefully described by the relative motions of active blocks and fault slip across block boundaries (Thatcher, 2007; Meade, 2007). Avouac and Tapponnier (1993) first attempt to describe the active deformation of central Asia using block model and long-term geologic slip rates across the bounding faults. Their model consists of four rigid blocks, e.g., India, Tibet, Tarim and Siberia. In their simulation, they take the whole Tibet as one rigid block, bounded on the north by Altyn Tagh, Qilian Shan, Haiyuan faults, and on the south by the Himalayan front. Their modeling provides a first-order description of the active tectonics of Tibet, such as lateral extrusion of eastern Tibet, the clockwise rotation of Tarim and its penetration into the Tianshan Mountain. But requiring 20-30 mm/a slip rate on the Altyn Tagh fault in their modeling is not compatible with current GPS observations (Wang et al, 2001). If we make a test based on their block boundary, replacing our model's related region by that of Avouac and Tapponnier (1993)'s model, the weighted RMS misfit of this model is $2.9 \mathrm{~mm} / \mathrm{a}$. This large misfit suggests that the Tibet cannot be taken as a coherent, rigid block. In fact, as shown by Peltzer and Saucier (1996)'s finite element model, the active faults within Tibet, such as the Kunlun, Xianshuihe, Karakorum-Jiali faults, cannot but accommodate certain parts of the convergence between Indian and Eurasian plates. These active faults, having slip rates ranging from 4 to $10 \mathrm{~mm} / \mathrm{a}$, account for $10 \%-30 \%$ of the convergence of Indian and Eurasian plates and should not 
be neglected (Peltzer and Saucier, 1996). If we use the block models proposed by Replumaz and Tapponnier (2003) and Chen et al (2004a, b) to simulate the GPS velocity field, the weighted RMS misfit is $2.4 \mathrm{~mm} / \mathrm{a}$ and $1.9 \mathrm{~mm} / \mathrm{a}$, respectively. Chen et al $(2004 \mathrm{a}, \mathrm{b})$ have divided the most deforming south Tibet into five blocks based on Yarlung Zangbo suture and the Yadong-Gulu and Thakkola rifts in order to describe tectonic processes, such as north-south contraction, east-west extension, eastward extrusion of Tibet. Meade (2007) has drawn the same conclusion in a similar modeling. The comparison of the RMS misfit between these different models suggests that a block model with including more small-size blocks in a deforming area would fit GPS data better, consistent with the concept noted by Replumaz and Tapponnier (2003).

In principle, the internal deformation should not be comparable to strain at the block boundary. Chen et al (2004a) propose a deforming block model that combines uniform strain with the motion of blocks to fit the GPS velocities, however, they determine a uniform strain rate that has a magnitude at $\sim 20 \times 10^{-9} / \mathrm{a}$ for the Tibet. We implement a similar strategy as Chen et al (2004a) have done, and obtain a better modeling because of the elaborate definition of block boundary with more data available. However, we suggest that the inclusion of strain parameters should be attributed more to technical need for numerical simulation purpose, and should be regarded as just a measure to accommodate the residuals between GPS observations and the block model itself. In reality, the internal deformation might not be uniform for these blocks and the residuals might represent heterogeneous internal straining or slow motion of smaller blocks, as analyzed by Thatcher (2007). And there might be several other reasons accounting for the strain parameters, which should not be attributed merely to continuous internal deformation, such as the uncertainties of GPS observations, the deviation of block boundary from real fault trace, irregular GPS station distribution, or possible unreasonable definition of block boundary. Our results show that the internal deformation is significant for some blocks within the Tibetan plateau, and these blocks have strain rates of $\sim 20 \times 10^{-9} / \mathrm{a}$ for the maximum principal extensional component. These internal strain rates might represent certain intrablock activities and possible motions of smaller blocks, indicating more complexity than is modeled using a single rigid block, hence, densified and evenly distributed networks, very complete temporal and spatial coverage may be neces- sary to precisely reveal such deformation and tectonic activities to improve the modeling (Thatcher, 2007). Our block model fitting the GPS data at an average misfit of about $1.5-1.7 \mathrm{~mm} / \mathrm{a}$ simply demonstrates that further refinement by elaborately defining block boundaries and downsizing some significantly deforming blocks within the Tibetan plateau is necessary with more data available.

Wang et al (2003) suggest that there does not exist a block with its scale more than $100000 \mathrm{~km}^{2}$ in Tibet, and hence, Zhang et al (2005) point out that present-day deformation of Chinese mainland can be described by a coupling model of continuous deformation in Tibet and rigid-block movement around its vicinity. Here, our analyses indicate that the present-day deformation in Tibet can be described by a finite number, small-size block rotations, without the necessity of the coupling model proposed by Zhang et al (2005). Owing to the difference of tectonic settings, geologic evolutions and strengths against the internal straining for each block, we suggest that the continental blocks may have diversified scales, as in the case of the global plate tectonics (Sella et al, 2002). Before the collision of Indian and Eurasian plates, the regions north of Yarlung Zangbo suture were comprised of several independent microplates or island arcs. Under the collision between Indian and Eurasian plates, the boundary forces of Indian plate's compression and shear implemented on the south Tibet are much more significant, compared to that of Philippine plate's impact on the South China, and as such, in Tibet, there might lack the tectonic conditions of forming completely rigid, coherent blocks sized as Tarim, South China blocks.

Although, as done by England and Molnar (2005), interpreting the large-scale deformation in Asia in terms of rotations of numerous block-elements, seems also applicable, technically speaking. But to describe this deformation by numerous elements and complex parameters, while ignoring the tectonic sense of each element and mechanical behavior of the discrete slip across major faults, is less economical than by a finite number, tectonic block rotations. As mentioned by Thatcher (2007), distinguishing between block and continuum models relies largely on the block scale, and the distinction between these two models becomes blurred as the number of faults increase and block size decreases. Our view is that $\sim 31$-element block model presented here, may be a preferable description of present-day deformation and the GPS velocity field in Asia. As for in Tibet, 
11-element block model, with averaged scale more than $200 \mathrm{~km} \times 200 \mathrm{~km}$, may be appropriate and important in quantifying regional tectonics. If considering the brittle-ductile transition layer in the upper crust as our model's bottom boundary, the ratio of vertical to lateral scale is $\sim 1: 10$, while considering the bottom of lithosphere as the vertical boundary, the ratio becomes $\sim 1: 2$. Thus, the tenet of plate tectonics may be applicable to characterize the present-day deformation in Tibet, probably in terms of upper crustal blocks (not lithospheric microplate); and at a larger scale, to describe the continental deformation in Asia, it is preferable rather a coupling model of upper crustal block and lithospheric microplate, than a coupling model of rigid-block movement and continuous deformation.

Using the measurements at 1683 GPS stations, we present a 31-element block model to describe present-day deformation of the Chinese mainland and its neighboring areas, which performs a better fit and reflects more tectonic features than previous block models. Under the collision between India and Eurasia plates, the active deformation of Chinese mainland can be largely explained by long-term crustal block rotations and elastic strain induced by the block-bounding fault locking. The slip rates inferred from the block model are in a range of $6-18 \mathrm{~mm} / \mathrm{a}$ for major faults in Tibet and its margins, and 1-4 mm/a in eastern China, consistent with geological observations. Our numerical simulation suggests that the crustal blocks deform internally at a level of $\sim 10 \times 10^{-9} / \mathrm{a}$, quite small in comparison with significant deformation localized along fault zones of $50-100 \mathrm{~km}$ wide. The goodness of fit suggests that the pattern of continental deformation is not continuous-like but block-like, and the tenet of plate tectonics may be applicable to characterize the active deformation in Asia.

Acknowledgements This study is supported by the National Natural Science Foundation of China (No. 40674054, 40774014 and 40974012), and Foundation of Institute of Seismology CEA (IS200856059). The authors are very grateful to the two anonymous reviewers for their careful and thoughtful comments.

\section{References}

Avouac J P and Tapponnier P (1993). Kinematic model of active deformation in central Asia. Geophys Res Lett 20: 895-898.

Banerjee P and Bürgmann R (2002). Convergence across the northwest Himalaya from GPS measurements. Geophys Res Lett 29(13): doi:10.1029/ 2002 GL015184.

Bendick R, Bilham R, Freymueller J, Larson K and Yin G H (2000). Geodetic evidence for a low slip rate in the Altyn Tagh fault and constraints on Asian deformation. Nature 404: 69-72.

Calais E, Vergnolle M, San'kov V, Lukhnev A, Miroshnitchenko A, Amarjargal $S$ and Déverchère $J$ (2003). GPS measurements of crustal deformation in the Baikal-Mongolia area (1994-2002): Implications for current kinematics of Asia. J Geophys Res 108(B10): 2 501, doi: 10.1029/2002JB002373.

Chen Q, Freymueller J T, Wang Q, Yang Z, Xu C and Liu J (2004a). A deforming block model for the present-day tectonics of Tibet. $J$ Geophys Res 109: B01403, doi:10.1029/2002JB002151.

Chen Q, Freymueller J T, Yang Z, Xu C, Jiang W, Wang Q, and Liu J (2004b). Spatially variable extension in southern Tibet based on GPS measurements. J Geophys Res 109: B09401, doi:10.1029 /2002JB002350.

Deng Q D, Zhang P Z, Ran Y K, Yang X P, Min W, and Chu Q Z (2002). Basic characteristics of active tectonics of China. Science in China (Series D) 32 1020-1 030 (in Chinese with English abstract).

England P and Molnar P (2005). Late Quaternary to decadal velocity fields in Asia. J Geophys Res 110: B12401, doi:10.1029/2004JB003541.

England P and Molnar P (1997). The field of crustal velocity in Asia calculated from Quaternary rates of slip on faults. Geophys J Int 130: 551-582.

Holt W E, Chamot-Rooke N, Le Pichon X, Haines A J, Shen-Tu B and Ren J W (2000).Velocity field in Asia inferred from Quaternary fault slip rates and Global Positioning System observations. J Geophys Res 105: 19 185-19209.

Li Y X, Yang G H, Li Z, Guo L Q, Huang C, Zhu W Y, Fu Y, Wang Q, Jiang Z $\mathrm{S}$ and Wang M (2003). Movement and strain conditions of active blocks in the Chinese mainland. Science in China (Series D) 33(Suppl.): 65-80 (in Chinese with English abstract).

McCaffrey R (2005). Block kinematics of the Pacific-North America plate boundary in the southwestern US from inversion of GPS, seismological, and geologic data. $J$ Geophys Res 110: B07401, doi:10.1029/ 2004JB003307.

Meade (2007). Present-day kinematics at the India-Asia collision zone. Geology 35(1): 81-84.

Niu Z J, Wang M, Sun H R, Sun J Z, You X Z, Gan W J, Xue G J, Hao J X, Xin S H, Wang Y Q, Wang Y X and Li B (2005). Contemporary velocity field of crustal movement of Chinese mainland from Global Positioning System measurements. Science Bulletin 50(8): 839-840 (in Chinese with English abstract).

Okada Y (1985). Surface deformation due to shear and tensile faults in a half-space. Bull Seism Soc Amer 75: 1 135-1 154.

Paul J, Bürgmann R, Gaur V K, Bilham R, Larson K M, Ananda M B, Jade S, Mukal M, Anupama T S, Satyal G and Kumar D (2001). The motion and active deformation of India. Geophys Res Lett 28(4): 647-650.

Peltzer G and Saucier F (1996). Present-day kinematics of Asia derived from geologic fault rates. J Geophys Res 101: 27 943-27956

Press W H, Flannery B P, Teukolsky S A and Vetterling W T (1989). Numerical Recipes. Cambridge University Press, Cambridge, 1-759.

Replumaz and Tapponnier (2003). Reconstruction of the deformed collision zone between India and Asia by backward motion of lithospheric blocks. $J$ Geophys Res 108(B6): 2 285, doi:10.1029/2001 JB000661.

Savage J C, Gan W and Svarc J L (2001). Strain accumulation and rotation in the eastern California shear zone. J Geophys Res 106: 21 995-22 007.

Savage J C (2000). Viscoelastic-coupling model for the earthquake cycle driven from below. $J$ Geophys Res 105: 25 525-25 532

Sella G F, Dixon T H and Mao A (2002). ReVEL: A model for recent plate motion velocities from space geodesy. $J$ Geophys Res 107(B4): 2081 , doi: $10.1029 / 2000 J B 000033$.

Thatcher W (2007). Microplate model for the present-day deformation of Tibet. $J$ Geophys Res 112(B1): B01401, doi: 10.1029/2005JB004244.

Vigny C, Socquet A, Rangin C, Chamot-Rooke N, Pubellier M, Bouin M N, Bertrand G and Becker M (2003). Present-day crustal deformation around Sagaing fault, Myanmar. J Geophys Res 108(B11): 2533, doi: 10.1029/ 002JB001999.

Wallace L M, Beavan J, McCaffrey R and Darby D (2004). Subduction zone coupling and tectonic block rotations in the North Island, New Zealand. $J$ Geophys Res 109: B12406, doi: 10.1029/2004JB003241.

Wang M, Shen Z K, Niu Z J, Zhang Z S, Sun H R, Gan W J, Wang Q and Ren Q (2003). Present-day crustal movement of Chinese mainland and active 
block model. Science in China (Series D) 33(Suppl.): 21-33 (in Chinese with English abstract).

Wang Q, Zhang P Z, Freymuller J, Bilham R, Larson K M, Lai X A, You X Z, Niu Z J, Wu J C, Li Y X, Liu J N, Yang Z Q and Chen Q (2001). Present-day crustal deformation in China constrained by GPS measurements. Science 294: 574-577.

Yang S M, Wang Q and You X Z (2005). Numerical analysis of contemporary horizontal tectonic deformation fields in China from GPS data. Acta Seismologica Sinica 2: 128-138 (in Chinese with English abstract).

Yang S M, Li J and Wang Q (2008). The deformation pattern and fault rate in the Tianshan Mountains inferred from GPS observations. Science in China (Series D) 51(8): 1 064-1 080 (in Chinese with English abstract).

Zhang P Z, Deng Q D, Zhang G M, Ma J, Gan W J, Min W, Mao F Y and Wang $Q$ (2003). Active tectonic blocks and strong earthquakes in the continent of China. Science in China (Series D) 33(Suppl.): 12-20.
Zhang P Z, Shen Z K, Wang M, Gan W J, Bürgmann R, Molnar P, Wang Q, Niu Z J, Sun J Z, Wu J C, Sun H R and You X Z (2004). Continuous deformation of the Tibetan Plateau from global positioning system data. $\mathrm{Ge}$ ology 32(9): 809-812.

Zhang P Z, Gan W J, Shen Z K and Wang M (2005). A coupling model of rigid-block movement and continuous deformation: Patterns of the present-day deformation of China's continent and its vicinity. Acta Geologica Sinica 79(06): 748-756 (in Chinese with English abstract).

Zhang Q and Zhu W Y (2000). The initial establishment of the tectonic block motion model of China from space geodetic data. Science Bulletin 45(9): 967-974 (in Chinese with English abstract).

\section{Appendix supplemental material to the text}

Table A1 The slip rates of strike-slip faults

\begin{tabular}{lrr}
\hline \multicolumn{1}{c}{ Fault name } & Strike-slip rate 1 & Strike-slip rate 2 \\
\hline Altyn Tagh (west) & $2.9 \pm 0.6$ & $1.1 \pm 1.0$ \\
Altyn Tagh (central) & $9.2 \pm 0.3$ & $7.5 \pm 0.6$ \\
Altyn Tagh (east) & $5.1 \pm 0.6$ & $5.5 \pm 1.4$ \\
Haiyuan & $3.0 \pm 0.3$ & $3.4 \pm 0.2$ \\
Nanqilianshan & $0.8 \pm 0.6$ & $0.4 \pm 0.3$ \\
Kunlun & $8.3 \pm 0.4$ & $6.7 \pm 0.9$ \\
Xianshuihe & $9.3 \pm 0.4$ & $6.9 \pm 0.8$ \\
Karakorum-Jiali (east) & $-4.3 \pm 1.4$ & $-3.2 \pm 3.0$ \\
Karakorum-Jiali (west) & $-2.0 \pm 1.4$ & $-1.0 \pm 1.4$ \\
Karakorum & $-5.6 \pm 1.3$ & $-4.4 \pm 2.6$ \\
Anning-Zemu-Xiaojiang & $8.4 \pm 0.4$ & $6.8 \pm 0.5$ \\
Red River & $-5.5 \pm 0.5$ & $-4.3 \pm 0.6$ \\
Nantinghe & $6.2 \pm 0.5$ & $4.2 \pm 0.7$ \\
Sagaing & $-24.0 \pm 1.0$ & $-16.5 \pm 1.2$ \\
Dienbienphu & $17.9 \pm 0.9$ & $10.3 \pm 1.8$ \\
Qinling-Dabie & $1.5 \pm 0.2$ & $-0.1 \pm 0.2$ \\
Tan-lu & $-2.0 \pm 0.2$ & $-1.6 \pm 0.2$ \\
Daqingshan & $1.5 \pm 0.2$ & $0.7 \pm 0.2$ \\
Zhangjiakou-Penglai & $1.8 \pm 0.1$ & $1.1 \pm 0.2$ \\
\hline
\end{tabular}

Note: The rate units are $\mathrm{mm} / \mathrm{a}$. The positive rates indicate left-lateral slip and the negative rates indicate right-lateral slip. Strike-slip rate 1 is the estimate when internal strain is not adjusted, and strike-slip rate 2 is the estimate when internal strain is adjusted.
Table A2 The slip rates of thrust or normal faults

\begin{tabular}{lcc}
\hline \multicolumn{1}{c}{ Fault name } & $\begin{array}{c}\text { Opening (or Dip-slip) } \\
\text { rate 1 }\end{array}$ & $\begin{array}{c}\text { Opening (or Dip-slip) } \\
\text { rate 2 }\end{array}$ \\
\hline Qilianshan & $-1.3 \pm 0.6$ & $-0.7 \pm 0.8$ \\
Shuanghu & $19.7 \pm 0.6$ & $16.6 \pm 1.8$ \\
Thakkola & $4.1 \pm 1.4$ & $4.7 \pm 1.7$ \\
Tangra-Yum & $5.4 \pm 1.4$ & $3.3 \pm 2.0$ \\
Yadong-gulu & $5.2 \pm 1.0$ & $5.0 \pm 1.5$ \\
Himalaya (west) & $-23.1 \pm 1.4$ & $-26.3 \pm 5.5$ \\
Himalaya (central) & $-19.7 \pm 0.9$ & $-19.1 \pm 1.4$ \\
Himalaya (east) & $-26.0 \pm 1.1$ & $-31.4 \pm 2.0$ \\
Lijiang-Xiaojinhe & $-3.2 \pm 0.6$ & $-0.8 \pm 0.7$ \\
Longmenshan & $-4.0 \pm 0.4$ & $-4.8 \pm 1.2$ \\
Yinchuan-Jilantai & $1.0 \pm 0.2$ & $0.1 \pm 0.2$ \\
ShanxiGraben & $0.8 \pm 0.1$ & $0.1 \pm 0.2$ \\
North Tianshan & $-1.1 \pm 0.5$ & $0.4 \pm 1.0$ \\
South Tianshan & $-12.4 \pm 0.5$ & $-9.4 \pm 1.0$ \\
Mountain (west) & & \\
South Tianshan & $-8.4 \pm 0.8$ & $-8.2 \pm 1.3$ \\
Mountain (east) & & \\
\hline
\end{tabular}

Note: The rate units are $\mathrm{mm} / \mathrm{a}$. The positive rates indicate extension and the negative rates indicate convergence. Opening (or Dip-slip) rate 1 is the estimate when internal strain is not adjusted, and Opening (or Dip-slip) rate 2 is the estimate when internal strain is adjusted. 